\title{
The protective effect of $\mathrm{L}$-arginine, tadalafil, and their combination in rat testes after ischemia and reperfusion injury
}

\author{
Gokhun Ozmerdiven, MD;' Burhan Coskun, MD;1 Onur Kaygisiz, MD;' Berna Aytac Vuruskan, MD;" \\ Burak Asiltas, MD; ${ }^{3}$ Hakan Kilicarslan, $M D^{1}$
}

Department of Urology; ${ }^{2}$ Department of Pathology; ${ }^{3}$ Department of Biochemistry; Uludag University, School of Medicine, Bursa, Turkey

Cite as: Can Urol Assoc J 2017;11(1-2):E19-25. http://dx.doi.org/10.5489/cuai.3872

Published online January 12, 2017

\section{Abstract}

Introduction: Nitric oxide (NO) plays an important role in the ischemia and reperfusion process. In this study, we aimed to examine the effect of L-arginine, tadalafil, and their combination for prevention of the ischemia reperfusion injury after testis torsion in rats. Methods: A total of 40 adult, male Sprague-Dawley rats were allocated into five groups. Three hours of left testicular torsion was performed in each group, excluding the control group. While the ischemia reperfusion (I/R) group had no treatment, $\mathrm{I} / \mathrm{R}+$ Arg group received $L$-arginine, $I / R+T d$ group received tadalafil and $I / R+A r g$ $+\mathrm{Td}$ group received tadalafil and L-arginine 30 minutes before the detorsion. Then the left testis was untwisted for four hours of reperfusion. After bilateral orchiectomy, lipid peroxidation (LPx) and glutathione $(\mathrm{GSH})$ activities were examined in testicular tissue. Spermatogenesis was evaluated with Johnsen's score.

Results: LPx levels of the I/R group were found to be significantly higher than for groups that received drugs for both testes $(p<0.001)$. GSH levels of the combination group were higher than I/R group in ipsilateral testis $(p<0.01)$ and it was significantly higher than other groups for contralateral testis $(p<0.001$ for $1 / R$ group, $p<0.01$ for $\mathrm{I} / \mathrm{R}+\operatorname{Arg}, \mathrm{p}<0.05$ for $\mathrm{I} / \mathrm{R}+\mathrm{Td}$ ). Mean Johnsen's score of the $\mathrm{I} / \mathrm{R}$ group was found to be significantly lower than treatment groups in ipsilateral testis $(p<0.001$ for $I / R+A r g+T d$ group, $p<0.01$ for other treatment goups) and contralateral testis $(p<0.001)$. The mean Johnsen score of the combination group was significantly higher than that of other treatment groups in ipsilateral testis $(p<0.05)$ and it was significantly higher than in the $I / R+T d$ group in the contralateral testis $(\mathrm{p}<0.05)$.

Conclusions: L-arginine, tadalafil, and combination of these two molecules showed protective effect against ischemia/reperfusion injury for both testes after unilateral testis torsion.

\section{Introduction}

Testicular torsion is a urological emergency that can result in ischemia and necrosis of the testicular tissue, commonly in young males and adolescents. ${ }^{1,2}$ Prompt surgical exploration and detorsion can contribute to salvaging the testis in $42-88 \%$ of cases. ${ }^{3,4}$ Even if the ipsilateral testis is salvaged, permanent damage can occur, depending on the degree and duration of the torsion. ${ }^{1}$ Furthermore, the contralateral testis can be affected and there is a risk of infertility in those cases. $^{2,5-7}$

Reperfusion of the ipsilateral testis after ischemia results in overproduction of reactive oxygen species (ROS), cytokines, and adhesion molecules, as well as migration of leucocytes. ${ }^{8.9}$ Nitric oxide (NO) - produced from L-arginine by nitric oxide synthase (NOS) - plays an important role in this process as a signaling molecule. NO leads to increased levels of cyclic guanosine monophosphate (cGMP), which may cause vasodilation and decreased adhesion of leucocytes. ${ }^{10}$ Several studies have reported a protective effect of $L$-arginine ( $\mathrm{NO}$ precursor) in ischemia-reperfusion (I/R) injury in rat testis torsion models. ${ }^{11,12}$

Tadalafil is a phosphodiesterase-5 (PDE5) inhibitor mostly used for treatment of erectile dysfunction. ${ }^{13}$ Inhibition of PDE5 enzymes may cause increased cGMP levels, ultimately resulting in smooth muscle relaxation. ${ }^{14}$ Several studies have been published indicating different PDE5 inhibitors, such as sildenafil and vardenafil, may have a protective effect in $\mathrm{I} / \mathrm{R}$ injury in rat testis models. ${ }^{15,16}$

The aim of this study was to investigate the effect of tadalafil (Td), L-arginine (Arg), and combination of these two drugs on testicular histology and markers of ischemia in an I/R injury model.

\section{Methods}

Following an approval from local ethical committee (No: 2013-09/01) a total of 40 male Sprague-Dawley rats, weighing 250-300 g, were included in the study. Rats were housed in a climate-controlled (temperature of $21-24^{\circ} \mathrm{C}$ ) room on a 12-hour light/12-hour dark cycle and with free access to food and water. 


\section{Surgical procedures}

All surgical procedures were performed under general anesthesia, using $1-2 \%$ sevoflurane and $100 \%$ oxygen on anesthesia apparatus. A $10 \%$ povidone iodine solution was used for cleaning of the scrotal skin and a $2 \mathrm{~cm}$ horizontal scrotal incision was made to take the left testis out; the right testis was kept in scrotum without any intervention. The left testis was twisted $720^{\circ}$ clockwise and attached to the wall of the scrotum with a $4 / 0$ silk suture to maintain ischemia for a three-hour period. Following removal of the suture, the testis was untwisted and put back to its original position to achieve reperfusion for another four hours. Finally, both testes were sacrificed for biochemical and histopathological examination.

\section{Groups}

The rats were allocated into five groups: Group 1 (control group, $\mathrm{n}=8$ ): left testis was not twisted and the rats underwent bilateral orchiectomy; Group 2 (I/R group, $n=8$ ): left testicular torsion was performed, whithout administration of any drug; Group 3 (I/R + Arg group, $\mathrm{n}=8)$ : $100 \mathrm{mg} / \mathrm{kg}$ of Arg was dissolved in $0.9 \% \mathrm{NaCl}$ and was given intraperitoneally 30 minutes before detorsion; Group $4(\mathrm{I} / \mathrm{R}+\mathrm{Td}$ group, $\mathrm{n}=8): 5 \mathrm{mg} / \mathrm{kg}$ of $\mathrm{Td}$ was dissolved in $0.9 \% \mathrm{NaCl}$ and given intraperitoneally 30 minutes before detorsion; and Group 5 $(\mathrm{I} / \mathrm{R}+\operatorname{Arg}+\mathrm{Td}$, combination group, $\mathrm{n}=8)$ : combination of Arg and $\mathrm{Td}(100 \mathrm{mg} / \mathrm{kg}$ of $\mathrm{Arg}$ and $5 \mathrm{mg} / \mathrm{kg}$ of $\mathrm{Td})$ was given intraperitoneally 30 minutes before detorsion.

\section{Lipid peroxidation assay}

The measurement of the tissue lipid peroxidation (LPx) level was taken with the thiobarbituric acid (TBA)-reactive substance assay, as described by Ohkawa et al. ${ }^{17} \mathrm{~A} 1.15 \% \mathrm{KCl}$ solution was used to homogenize $250 \mathrm{mg}$ of testis tissue and $0.2 \mathrm{ml}$ of $1.8 \%$ sodium dodecyl sulfate (SDS), $1.5 \mathrm{ml}$ of $20 \%$ acetic acid solution (pH 3.5), $0.8 \%$ TBA and $0.6 \mathrm{ml}$ distilled water were added to $0.2 \mathrm{ml}$ of tissue homogenate. The mixtures were heated at $95^{\circ} \mathrm{C}$ for one hour. After cooling with tap water, $5 \mathrm{ml}$ of the mixture of $\mathrm{n}$-butanol and pyridine $(15: 1, v / v)$ was added and then centrifuged at 4000 rpm for $20 \mathrm{~min}$. This organic layer was measured at $532 \mathrm{~nm}$ absorbance. 1,1,3,3-tetramethoxypropane (TMP) was used as an external standard, and the level of lipid peroxides was expressed as $\mathrm{nmol} / \mathrm{mg}$ wet tissue.

\section{Glutathione assay}

Glutathione (GSH) content of tissue homogenate was measured at $412 \mathrm{~nm}$ using the method of Sedlak and Lindsay; ${ }^{18}$ $500 \mathrm{mg}$ of testis tissues were homogenized in $1.15 \% \mathrm{KCl}$, then $1 \mathrm{ml}$ homogenate was added to $2 \mathrm{ml}$ of $10 \%$ trichloro- acetic acid that included $5 \mathrm{mmol}$ ethylenediaminetetraacetic acid (EDTA) solution. The mixture was centrifuged (10000 $\mathrm{g}$ for 10 minutes). A mixture of $0.4 \mathrm{ml}$ of supernatant with $2.5 \mathrm{ml}$ potassium phosphate tamponade (ph 8.4) and 0.1 ml DTNB (5.5'-dithio-bis-2-nitrobenzoic acid) was prepared. The solution was kept at room temperature for 20 minutres, and then read at $412 \mathrm{~nm}$ on the spectrophotometer. Results were expressed as $\mathrm{nmol} / \mathrm{g}$ protein.

\section{Histopathological examination}

Neutral $10 \%$ buffered formalin solution was used to fix the testicular tissue samples. After insertion into paraffin wax, testicular tissue was split in to $3 \mathrm{~mm}$ sections and stained with hematoxylin and eosin. Histological examination was carried out under a light microscope and spermatogenesis was evaluated with Johnsen's score. ${ }^{19}$ According to Johnsen's criteria, a score ranging between 1 and 10 was determined in all cross-sectioned tubules. While a score of 1 represents the worst score, 10 represents an excellent spermatogenesis.

\section{Statistical analysis}

The statistical data were analyzed using Statistical Package for the Social Sciences (SPSS, Chicago, IL, U.S.) version 22.0 for Windows. All values were expressed as mean \pm standard deviation (SD). The non-parametric Kruskal-Wallis test was used to determine the significant differences among the groups. Mann-Whitney $U$ test, compared the differences between the groups. P values less than 0.05 were considered statistically significant.

\section{Results}

\section{Biochemical examination of the testis}

The I/R group had significantly higher mean level of LPX and lower score of GSH when compared to control group in both testes $(\mathrm{p}<0.001)$ (Tables 1, 2; Figs. 1A,1B, 2A, 2B).

Arg administration ( $I / R+A r g)$ resulted in significantly lower mean values of LPx when compared to $\mathrm{I} / \mathrm{R}$ group in ipsilateral and contralateral testis $(p<0.01$ and $p<0.001$, respectively). GSH levels of the $\mathrm{I} / \mathrm{R}+$ Arg group were not significantly different when compared to I/R group in both testes (Tables 1, 2; Figs. 1A,1B, 2A, 2B).

$\mathrm{Td}$ administration $(\mathrm{I} / \mathrm{R}+\mathrm{Td})$ also resulted in significantly lower mean values of LPx when compared to I/R group in ipsilateral and contralateral testis $(p<0.01$ and $p<0.001$, respectively). GSH levels were similar when compared to I/R group in ipsilateral testis. However, GSH levels were significantly higher than in $\mathrm{I} / \mathrm{R}$ group in contralateral testis $(\mathrm{p}=0.042)$ (Tables 1, 2; Figs. 1A,1B, 2A, 2B). 

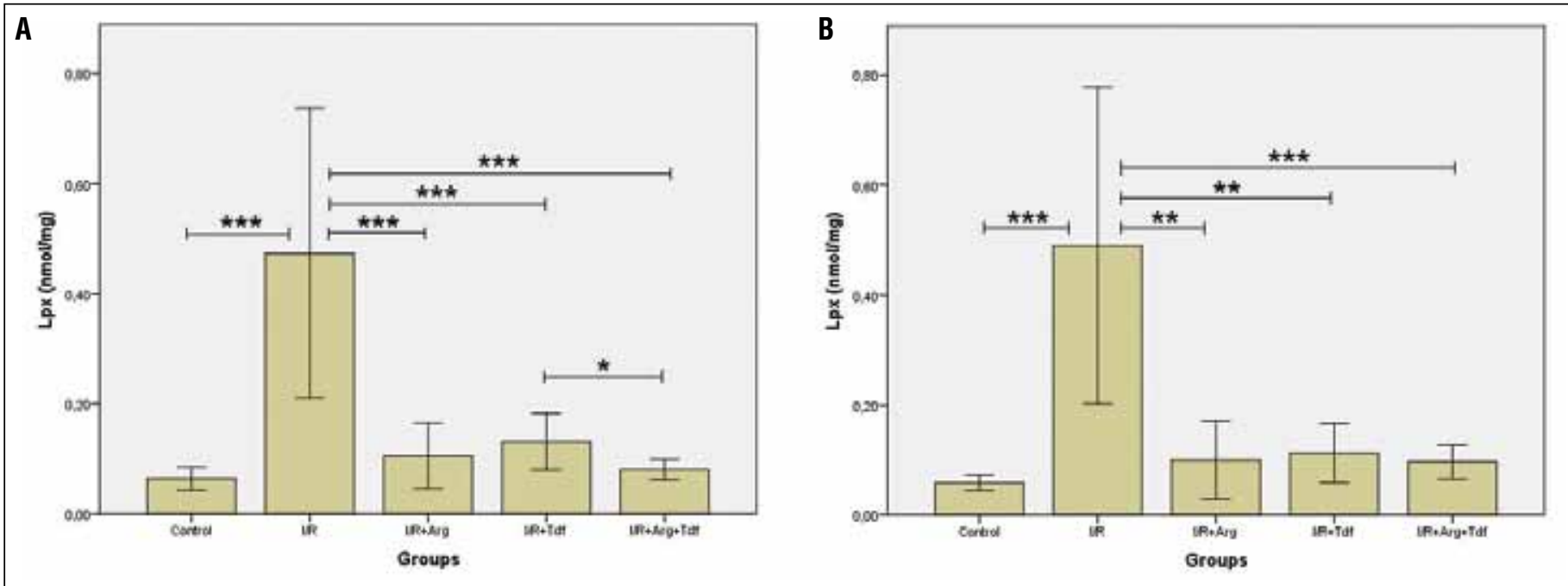

Fig. 1. (A) Comparison of Lpx levels in ipsilateral testis; $p<0.05$ Mann-Whitney $U$ test, bar represent mean \pm standard deviation (SD) values; (B) comparison of $L p x$ levels in contralateral testis; $p<0.05$ Mann-Whitney U test, bar represent mean \pm SD values. ${ }^{* * *} p<0.001 ;{ }^{* *} p<0.01 ;{ }^{*} p<0.05$. Arg: L-arginine; l/R: ischemia/reperfusion; Lpx: lipid peroxidation; Tdf: tadalafil.

The combination group $(\mathrm{I} / \mathrm{R}+\mathrm{Arg}+\mathrm{Td})$ showed significantly lower levels of $\operatorname{LPx}(\mathrm{p}<0.001)$ and higher scores of GSH when compared to I/R group for both testes $(p<0.01$ for ipsilateral, $\mathrm{p}<0.001$ for contralateral) (Tables 1, 2; Figs. $1 \mathrm{~A}, 1 \mathrm{~B}, 2 \mathrm{~A}, 2 \mathrm{~B})$. Comparison of the combination group with other treatment groups revealed no significant difference in LPx levels of the ipsilateral testis. However, Lpx levels of the ipsilateral testis were significantly lower than in the $\mathrm{I} / \mathrm{R}+\mathrm{Td}$ group in contralateral testis $(p=0.028)$. Furthermore, $G S H$ levels of the combination group were significantly higher than in the $\mathrm{I} / \mathrm{R}+\mathrm{Arg}$ and $\mathrm{I} / \mathrm{R}+\mathrm{Td}$ groups in contralateral testis ( $p<0.01$ and $p=0.01$, respectively) (Tables 1,2 ; Figs. $1 \mathrm{~A}, 1 \mathrm{~B}, 2 \mathrm{~A}, 2 \mathrm{~B})$.

\section{Histopathological examination}

The histopathological examination of the both testes with light microscope was normal in the control group. The I/R group had widespread areas of necrosis in both testis, especially in the ipsilateral testis; furthermore, edema and congestion were noted. The I/R + Arg and I/R + Td groups had increased edema and congestion; these was not observed in the $\mathrm{I} / \mathrm{R}+\mathrm{Arg}+\mathrm{Td}$ group for either testes (Fig.3).

The mean Johnsen's score of the I/R group was significantly lower than the control group in both testis $(p<0.001)$
(Tables 1, 2; Fig. 4A, 4B). The $\mathrm{I} / \mathrm{R}+\mathrm{Arg}$ and $\mathrm{I} / \mathrm{R}+\mathrm{Td}$ groups had significantly higher scores when compared to the $I / R$ group for ipsilateral and contralateral testis $(p<0.01$ and $\mathrm{p}<0.001$, respectively) (Tables 1,2 ; Figs. 4A,4B). The combination group $(I / R+A r g+T d)$ showed higher scores when compared to I/R group for both testes $(p<0.001)$ (Tables 1, 2; Fig. 4A, 4B). Furthermore, the combination group had better scores when compared to each treatment group for ipsilateral testis and $\mathrm{Td}$ for contralateral testis $(p=0.038)$ (Tables 1, 2; Figs. 4A, 4B).

\section{Discussion}

The results of the present study indicated higher levels of lipid peroxydation, lower levels of antioxidant capacity, and impaired testicular histology not only for ipsilateral testis, but also for contralateral testis. Testicular torsion results in discontinuation of perfusion on effected testis. Following reperfusion, testicular damage further increases by formation of ROS. ${ }^{8}$

The condition of the contralateral testis after I/R is conflicting in the literature. Several studies have reported impairment of the contralateral testis. ${ }^{20-22}$ The rationale behind the damage in contralateral testis was explained by autoimmunization against spermatogonium, a process caused by

\begin{tabular}{lcccccc}
\hline \multicolumn{7}{l}{ Table 1. LPx and GSH levels and Johnsen scores in ipsilateral testis } \\
\hline Tissue parameters & $\begin{array}{c}\text { Group 1: } \\
\text { Control }\end{array}$ & $\begin{array}{c}\text { Group 2: } \\
\text { I/R }\end{array}$ & $\begin{array}{c}\text { Group 3: } \\
\text { I/R + Arg }\end{array}$ & $\begin{array}{c}\text { Group 4: } \\
\text { I/R + Tdf }\end{array}$ & $\begin{array}{c}\text { Group 5: } \\
\text { I/R + Arg + Tdf }\end{array}$ & p* \\
\hline LPx & $0.058 \pm 0.140$ & $0.49 \pm 0.288$ & $0.10 \pm 0.070$ & $0.112 \pm 0.053$ & $0.096 \pm 0.031$ & $<0.001$ \\
GSH & $9869 \pm 2461$ & $6651 \pm 1413$ & $7696 \pm 1557$ & $8048 \pm 1429$ & $8621 \pm 1154$ & 0.021 \\
Johnsen score & $9.737 \pm 0.13$ & $6.862 \pm 0.531$ & $7.975 \pm 0.26$ & $7.825 \pm 0.449$ & $8.525 \pm 0.416$ & $<0.001$ \\
\hline \multicolumn{7}{l}{ Data is expressed as mean \pm standard deviation. *p for Kruskal-Wallis test. Arg: L-arginine; I/R: ischemia/reperfusion; GSH: glutathion; Lpx: lipid peroxidation; Tdf: tadalafil. }
\end{tabular}



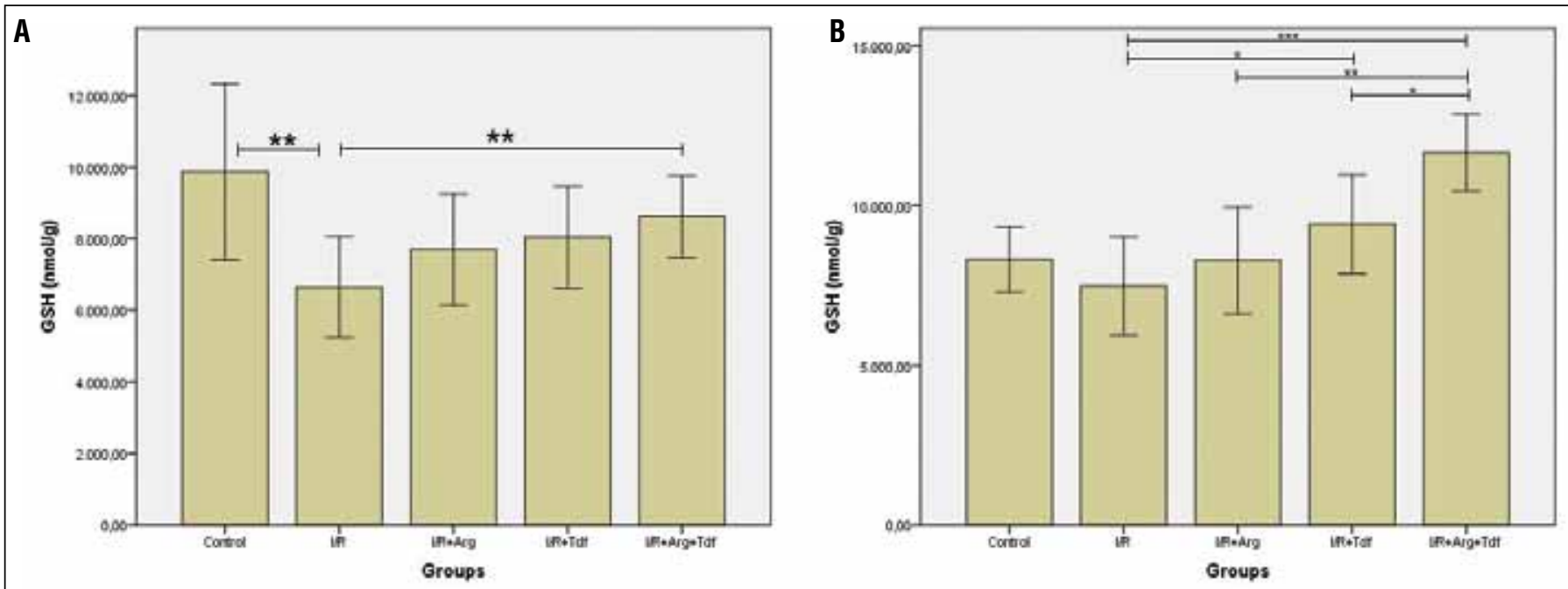

Fig. 2. (A) Comparison of GSH levels in ipsilateral testis $p<0.05$ Mann-Whitney $U$ test; bar represent mean \pm standard deviation (SD) values; (B) comparison of GSH levels in contralateral testis; $p<0.05$ Mann-Whitney U test, bar represent mean \pm SD values. ${ }^{* * *} p<0.001 ;{ }^{* *} p<0.01 ;{ }^{*} p<0.05$. Arg: L-arginine; GSH: glutathione; I/R: ischemia/reperfusion; Tdf: tadalafil.

impaired blood-sperm barrier, reduction of the blood flow by reflex sympathetic response, and over-production of the ROS following reperfusion. ${ }^{23-25}$ There are also several studies that report no effect of testicular torsion on contralateral testis. ${ }^{25,26}$

ROS over production, inflammatory response, and lipid peroxidation are important steps in I/R injury. ${ }^{8,27} \mathrm{NO}$ plays a major role in inflammatory response after reperfusion. Although being a free oxygen radical itself, NO regulates the severity of the inflammatory process, such as decreasing leucocyte infiltration and inflammatory cytokines. ${ }^{28}$

The idea of providing $\mathrm{NO}$ to the ischemic tissue before reperfussion has gained interest and Arg was used for this purpose in a few studies. Dokucu et al reported a protective effect of Arg on testicular histology of the controlateral testis following an ischemia period of six hours. ${ }^{11}$ The authors evaluated testicular tissue 21 days after I/R and speculated $\mathrm{NO}$ was acting as a vasodilator to protect testis. Similarly, Barlas et al found Arg-infused rats had reduced reperfusion injury in a 30-minute torsion/detrosion model. ${ }^{12}$ However, Ozokutan et al found increased damage with Arg after four hours of torsion/detorsion in a rat model. ${ }^{29}$

The PDE5 inhibitors were originally developed for treatment of erectile dysfunction and today these molecules can be used in other diseases, such as benign prostate hyper- plasia and pulmonary hypertension. ${ }^{13,30,31}$ The effect of PDE5 inhibitors on testicular torsion is conflicting in the literature. Beheshtian et al demonstrated beneficial effects of sildenafil administration before detorsion in an $\mathrm{I} / \mathrm{R}$ rat model. They reported increased levels of antioxidant enzyme levels, decreased levels of lipid peroxidation, and germ cell apoptosis. $^{32}$ Similarly protective effects of low-dose sildenafil on contralateral testis were reported in another study $i^{15}$ however, they found high-dose sildenafil had no protective effect on testis histopathologically or biochemically. In another study, vardenafil administration was found to have protective effects in rat testis after 30 minutes of torsion and four hours reperfusion. ${ }^{16}$ Contrary results were reported with sildenafil or vardenafil administration after one hour of ischemia and two hours of reperfusion in yet another study. ${ }^{33}$

The main outcome from the present study indicates $\mathrm{Td}$ and Arg combination has better results when compared to each treatment group alone, especially in contralateral testis. To the best of our knowledge, this is the first study reporting superiority of this combination. We speculate the combination of these two molecules may have a synergistic effect on vasodilation and suppression of local immune response after reperfusion.

\begin{tabular}{lcccccc}
\hline \multicolumn{7}{l}{ Table 2. LPx and GSH levels and Johnsen scores in contralateral testis } \\
\hline Tissue parameters & $\begin{array}{c}\text { Group 1: } \\
\text { Control }\end{array}$ & $\begin{array}{c}\text { Group 2: } \\
\text { I/R }\end{array}$ & $\begin{array}{c}\text { Group 3: } \\
\text { I/R + Arg }\end{array}$ & $\begin{array}{c}\text { Group 4: } \\
\text { I/R + Tdf }\end{array}$ & $\begin{array}{c}\text { Group 5: } \\
\text { I/R + Arg + Tdf }\end{array}$ & p* \\
\hline LPx & $0.063 \pm 0.020$ & $0.473 \pm 0.263$ & $0.105 \pm 0.059$ & $0.113 \pm 0.051$ & $0.08 \pm 0.0180$ & $<0.001$ \\
GSH & $8309 \pm 1016$ & $7481 \pm 1540$ & $8276 \pm 1668$ & $9421 \pm 1546$ & $11625 \pm 1200$ & 0.001 \\
Johnsen score & $9.775 \pm 0.175$ & $7.237 \pm 0.388$ & $8.837 \pm 0.311$ & $8.812 \pm 0.269$ & $9.120 \pm 0.183$ & $<0.001$ \\
\hline \multicolumn{4}{l}{ Dates is expressed as mean \pm standard deviation. *p for Kruskal-Wallis test. Arg: L-arginine; I/R: ischemia/reperfusion; GSH: glutathion; Lpx: lipid peroxidation; Tdf: tadalafil. }
\end{tabular}




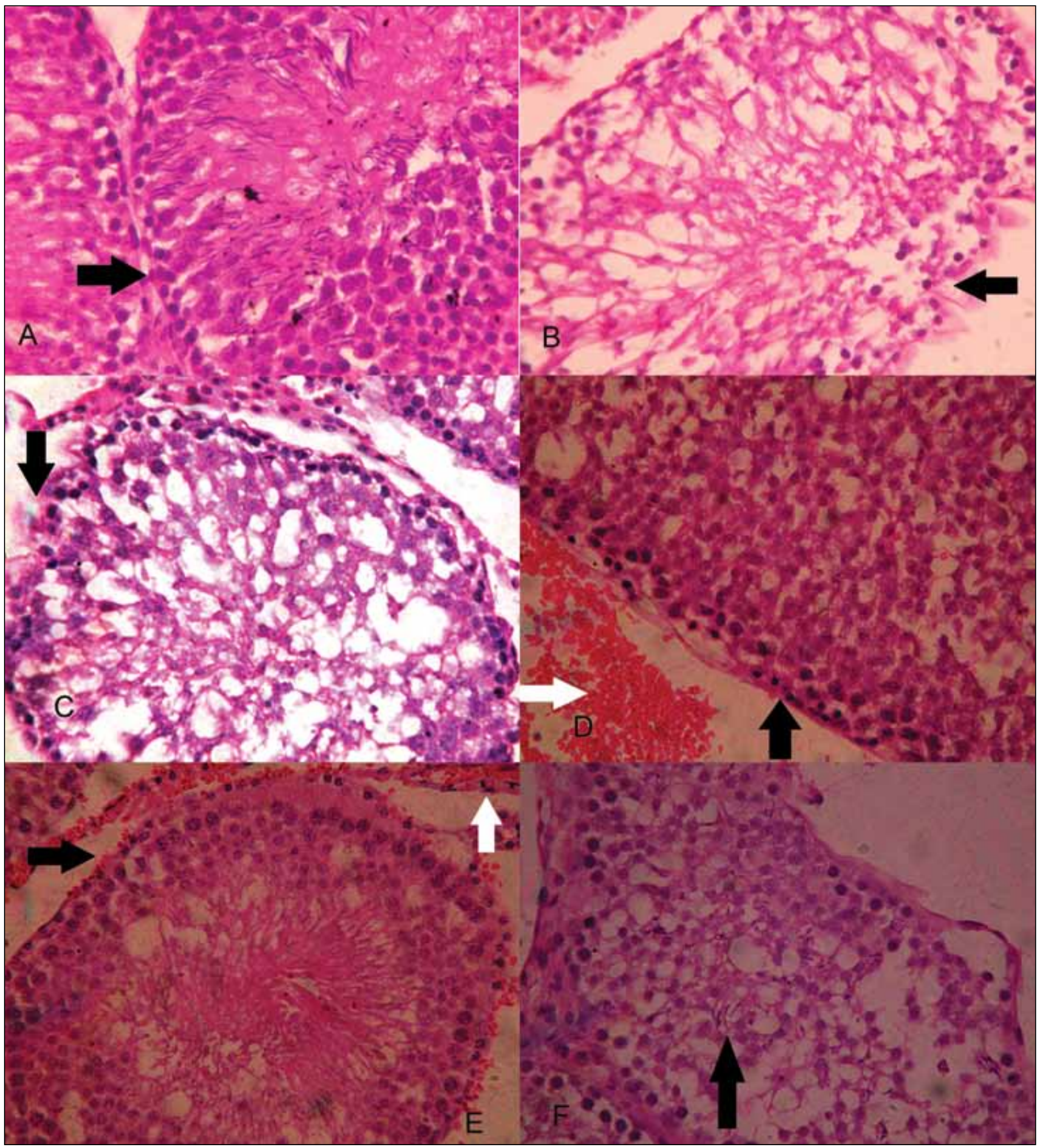

Fig. 3. (A) Normal morphological appearance of seminiferous tubule; spermatids are present in ipsilateral testis of control group (black arrow); (B) maturation arrest of germ cells, desquamation and disorganization of germ cell layer in ipsilateral testis of ischemia/reperfusion (I/R) group (black arrow); (C) maturation arrest, desquamation, and disorganization of germ cell layer in contralateral testis of I/R group; (D) degeneration and maturation arrest in germinal cells was noticed in ipsilateral testis of I/R + L-arginine group and spermatocytes were preserved (black arrow). Hemorrhage and edema around the vessels were noticed (white arrow); (E) degeneration and maturation arrest in germinal cells was noticed in ipsilateral testis of $\mathrm{l} / \mathrm{R}+$ tadalafil group and spermatocytes were preserved (black arrow). Hemorrhage and edema around the vessels were noticed (white arrow); $(\boldsymbol{F})$ in combination group hemorrhage and edema was not evident in ipsilateral testis. A better level of maturation of spermatids were recognized than in other treatment groups (black arrow). 

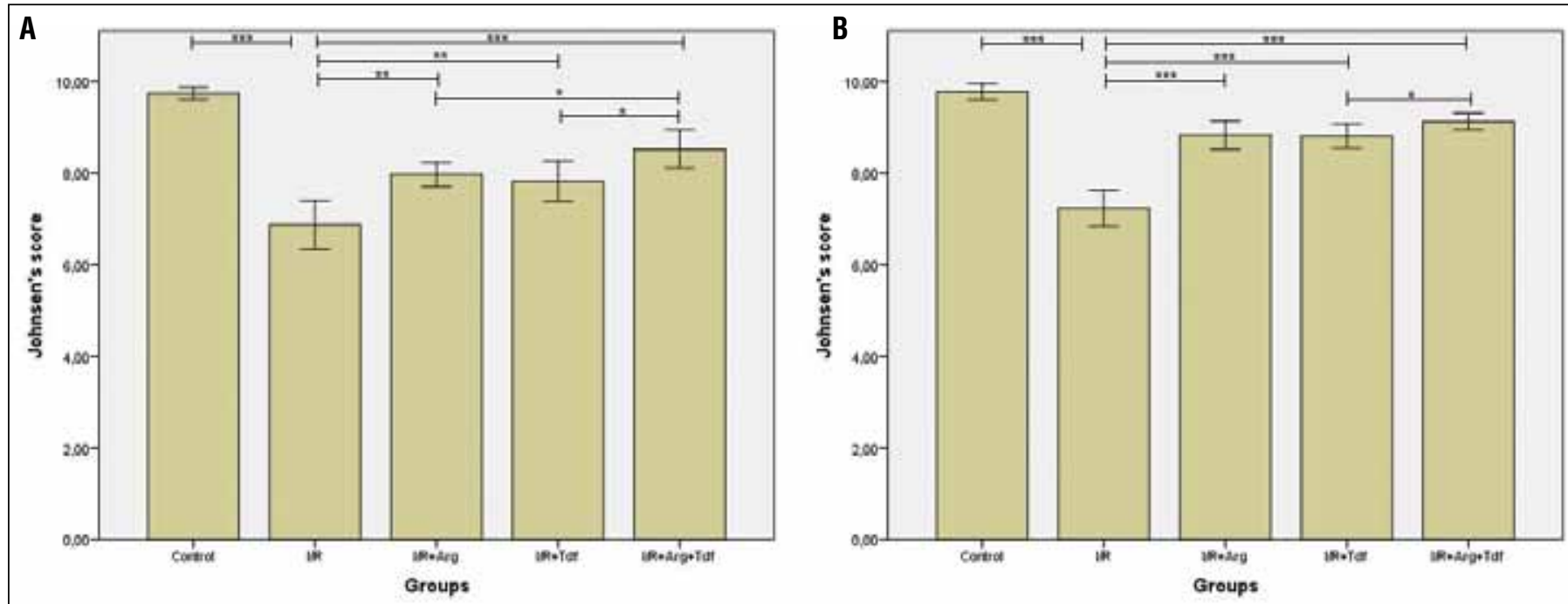

Fig. 4. (A) Comparison of mean Johnsen's scores in ipsilateral testis; $p<0.05$ Mann-Whitney $U$ test, bar represent mean \pm standard deviation (SD) values; (B) comparison of mean Johnsen's scores in contralateral testis; $\mathrm{p}<0.05$ Mann-Whitney U test, bar represent mean $\pm \mathrm{SD}$ values. ${ }^{* *} \mathrm{p}<0.001 ;{ }^{* *} \mathrm{p}<0.01 ;{ }^{*} \mathrm{p}<0.05$. Arg: arginin; I/R: ischemia/reperfusion; Tdf: tadalafil.

\section{Conclusion}

Unilateral testicular torsion has a hazardous effects for both testes in rats. Administration of Arg or Td has protective effects on both testes. Combination of these two molecules results in reduction of lipid peroxidation, increase of antioxidant capacity, and better preservation of the testicular histology. This is more evident in contralateral testis, which is important for preservation of fertility in cases where salvage of the testis is not possible. Human studies are needed for consideration of these molecules in clinical use.

Competing interests: The authors report no competing personal or financial interests.

This paper has been peer-reviewed.

\section{References}

1. Pentyala S, Lee J, Yalamanchili P, et al. Testicular torsion: A review. J Low Genit Tract Dis 2001;5:38-7. https://doi.org/10.1097/00128360-200101000-00008

2. Visser AJ, Heyns CF. Testicular function after torsion of the spermatic cord. BJU Int 2003;92:200-3. hitps://doi.org/10.1046/i.1464-410X.2003.04307.x

3. Saba $M$, Morales CR, De Lamirande E, et al. Morphological and biochemical changes following acute unilateral testicular torsion in prepubertal rats. J Urol 1997;157:1149-54. https://doi.org/10.1016/ S0022-5347(01)65158-9

4. Cattolica EV, Karol JB, Rankin KN, et al. High testicular salvage rate in torsion of the spermatic cord. J Urol 1982;128:66-8.

5. Mogilner JG, Lurie $M$, Coran AG, et al. Effect of diclofenac on germ cell apoptosis following testicular ischemia-reperfusion injury in a rat. Pediatr Surg Int 2006;22:99-105. https://doi.org/10.1007/ s00383-005-1580-9

6. Anderson MJ, Dunn JK, Lipshultz LI, et al. Semen quality and endocrine parameters after acute testicular torsion. J Urol 1992;147:1545-50.

7. Nagler HM, White RD. The effect of testicular torsion on the contralateral testis. J Urol 1982;128:1343-8.
8. Zimmerman BJ, Granger DN. Reperfusion injury. Surg Clin North Am 1992;72:65-83. https://doi.org/10.1016/S0039-6109(16)45628-8

9. Reilly PM, Schiller HJ, Bulkley GB. Pharmacologic approach to tissue injury mediated by free radicals and other reactive oxygen metabolites. Am J Surg 1991;161:488-503. https://doi.org/10.1016/00029610(91)91120-8

10. Kannan MS, Guiang S, Johnson DE. Nitric oxide: Biological role and clinical uses. Indian J Pediatr 1998;65:333-45. https://doi.org/10.1007/BF02761123

11. Dokucu Al, Ozturk H, Ozdemir $E$ et al. The protective effects of nitric oxide on the contralateral testis in prepubertal rats with unilateral testicular torsion. BJU Int 2000;85:767-71. https://doi.org/10.1046/ j.1464-410x.2000.00529.x

12. Barlas $M$, Hatiboglu $C$. The effect of nitric oxide in testicular ischemia-reperfusion injury. Int Urol Nephrol 2002;34:81-6. https://doi.org/10.1023/A:1021311029572

13. van Driel MF. Phosphodiesterase inhibitors: Effectiveness and new applications. Ned Tiidschr Geneeskd 2006;150:1613-6.

14. Corbin JD, Francis SH. Pharmacology of phosphodiesterase-5 inhibitors. Int I Clin Pract 2002;56:453-9.

15. Yildiz H, Durmus AS, Simsek H, et al. Protective effect of sildenafil citrate on contralateral testis injury after unilateral testicular torsion/detorsion. Clinics (Sao Paulo) 2011;66:137-42.

16. Erol B, Tokgoz H, Hanci V, et al. Vardenafil reduces testicular damage following ischemia/reperfusion injury in rats. Kaohsiung J Med Sci 2009;25:374-80. https://doi.org/10.1016/S1607-551X(09)70530-3

17. Ohkawa H, Ohishi N, Yagi K. Reaction of linoleic acid hydroperoxide with thiobarbituric acid. J Lipid Res 1978; 19:1053-7.

18. Sedlak J, Lindsay RH. Estimation of total, protein-bound, and non-protein sulfhydryl groups in tissue with Ellman's reagent. Anal Biochem 1968;25:192-205. https://doi.org/10.1016/0003-2697(68)90092-4

19. Johnsen SG. Testicular biopsy score count - a method for registration of spermatogenesis in human testes: Normal values and results in 335 hypogonadal males. Hormones 1970;1:2-25. https://doi.org/10.1159/000178170

20. Shimizu S, Saito M, Dimitriadis F et al. Protective effect of ischemic post-conditioning on ipsilateral and contralateral testes after unilateral testicular ischemia reperfusion injury. Int J Androl 2011;34:268-75. https://doi.org/10.1111/i.1365-2605.2010.01077.x

21. Harrison RG, Lewis-Jones DI, Moreno de Marval MJ, et al. Mechanism of damage to the contralateral testis in rats with an ischemic testis. Lancet 1981;2:723-5. https://doi.org/10.1016/S01406736(81)91050-3

22. Shiraishi K, Naito K, Yoshida K. Nitric oxide promotes germ cell necrosis in the delayed phase after experimental testicular torsion of rat. Biol Reprod 2001;65:514-21. https://doi.org/10.1095/biolreprod65.2.514

23. Lewis-Jones DI, Moreno de Marval M, Harrison RG. Impairment of rat spermatogenesis following unilateral experimental ischemia. Fertil Steril 1982;38:482-90. https://doi.org/10.1016/S00150282(16)46585-4 
24. Sarica K, Kupeli B, Budak M, et al. Influence of experimental spermatic cord torsion on the contralateral testis in rats. Evaluation of tissue free oxygen radical scavenger enzyme levels. Urol Int 1997;58:208-12. https://doi.org/10.1159/000282985

25. Madgar I, Lunenfeld B, Mashiach S, et al. Effect of testicular torsion on contralateral testis and fertility in mature rats. Arch Androl 1987;19:237-41. https://doi.org/10.3109/01485018708986822

26. Turner TT. Acute experimental testicular torsion. № effect on the contralateral testis. J Androl 1985;6:6572. https://doi.org/10.1002/i.1939-4640.1985.tb00817.x

27. Cuzzocrea S, Riley DP, Caputi AP, et al. Antioxidant therapy: A new pharmacological approach in shock, inflammation, and ischemia/reperfusion injury. Pharmacol Rev 2001;53:135-59.

28. Phillips L, Toledo AH, Lopez-Neblina F, et al. Nitric oxide mechanism of protection in ischemia and reperfusion injury. J Invest Surg 2009;22:46-55. https://doi.org/10.1080/08941930802709470

29. Ozokutan BH, Kucukaydin $M$, Muhtaroglu $S$, et al. The role of nitric oxide in testicular ischemia-reperfusion injury. J Pediatr Surg 2000;35:101-3. https://doi.org/10.1016/S0022-3468(00)80023-8

30. Porst H, McVary KT, Montorsi $F$, et al. Effects of once-daily tadalafil on erectile function in men with erectile dysfunction and signs and symptoms of benign prostatic hyperplasia. Eur Urol 2009;56:727-35. https://doi.org/10.1016/i.eururo.2009.04.033
31. de Carvalho AC, Hovnanian AL, Fernandes CJ, et al. Tadalafil as treatment for idiopathic pulmonary arterial hypertension. Arq Bras Cardiol 2006;87:195-7. https://doi.org/10.1590/S0066$782 \times 2006001800027$

32. Beheshtian A, Salmasi AH, Payabvash S, et al. Protective effects of sildenafil administration on testicular torsion/detorsion damage in rats. World J Urol 2008;26:197-202. https://doi.org/10.1007/s00345008-0243-6

33. Ustun H, Akgul KT, Ayyildiz A, et al. Effect of phospodiesterase 5 inhibitors on apoptosis and nitric oxide synthases in testis torsion: an experimental study. Pediatr Surg Int 2008;24:205-11. https://doi.org/10.1007/s00383-007-2058-8

Correspondence: Dr. Gokhun Ozmerdiven, Department of Urology, Uludag University, School of Medicine, Bursa, Turkey; gozmerdiven@gmail.com 